\author{
OAK RIDGE \\ NATIONAL LABORATORY \\ MANAGED BY UT-BATTELLE \\ FOR THE DEPARTMENT OF ENERGY
}

Final Report

for

CRADA No. NFE-08-01377

with

Nu-Energie LLC

\title{
A COMBINED REACTION/PRODUCT RECOVERY PROCESS FOR THE CONTINUOUS PRODUCTION OF BIODIESEL
}

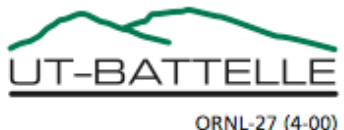


Reports produced after January 1, 1996, are generally available free via the U.S. Department of Energy (DOE) Information Bridge.

Web site http://www.osti.gov/bridge

Reports produced before January 1, 1996, may be purchased by members of the public from the following source.

National Technical Information Service

5285 Port Royal Road

Springfield, VA 22161

Telephone 703-605-6000 (1-800-553-6847)

TDD 703-487-4639

Fax 703-605-6900

E-mail info@ntis.fedworld.gov

Web site http://www.ntis.gov/support/ordernowabout.htm

Reports are available to DOE employees, DOE contractors, Energy Technology Data Exchange (ETDE) representatives, and International Nuclear Information System (INIS)

representatives from the following source.

Office of Scientific and Technical Information

P.O. Box 62

Oak Ridge, TN 37831

Telephone 865-576-8401

Fax 865-576-5728

E-mail reports@adonis.osti.gov

Web site http://www.osti.gov/contact.html

This report was prepared as an account of work sponsored by an agency of the United States Government. Neither the United States Government nor any agency thereof, nor any of their employees, makes any warranty, express or implied, or assumes any legal liability or responsibility for the accuracy, completeness, or usefulness of any information, apparatus, product, or process disclosed, or represents that its use would not infringe privately owned rights. Reference herein to any specific commercial product, process, or service by trade name, trademark, manufacturer, or otherwise, does not necessarily constitute or imply its endorsement, recommendation, or favoring by the United States Government or any agency thereof. The views and opinions of authors expressed herein do not necessarily state or reflect those of the United States Government or any agency thereof. 


\title{
A COMBINED REACTION/PRODUCT RECOVERY PROCESS FOR THE CONTINUOUS PRODUCTION OF BIODIESEL
}

\author{
Final Report \\ Oak Ridge National Laboratory \\ Oak Ridge TN \\ J.F. Birdwell Jr. \\ J. McFarlane \\ D.L. Schuh \\ C. Tsouris \\ Nu-Energie, LLC \\ Surgoinsville TN \\ J.N. Day \\ B.S. Hullette \\ September 2009
}




\section{Table of Contents}

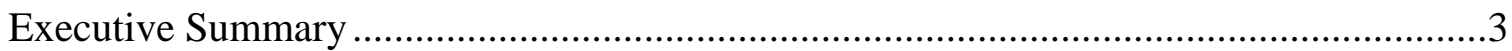

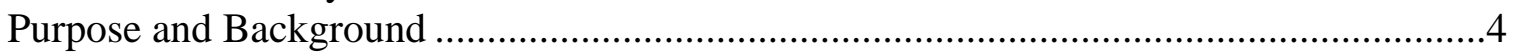

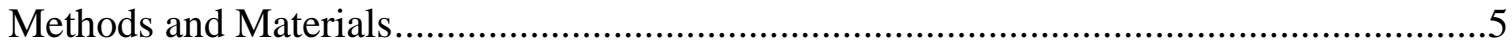

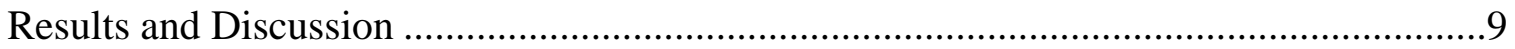

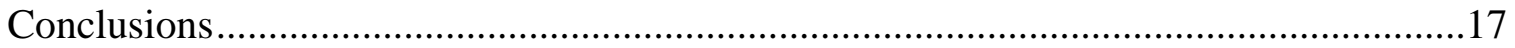

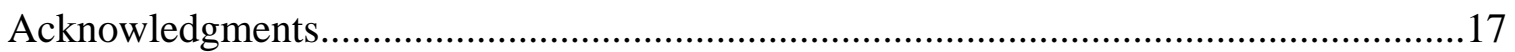

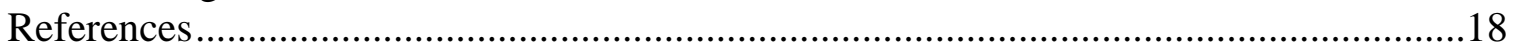

Appendix A Task Descriptions in Scope of Work......................................................19

\section{Table of Figures}

Figure 1: Schematic of Standard Centrifugal Contactor................................................5

Figure 2: Calibration curve of viscosity as a function of bound glycerine ..........................8

Figure 3: GC analysis of less-dense fluid from continuous production of biodiesel. .......11

Figure 4: GC analysis of more-dense fluid from continuous production of biodiesel. .....11

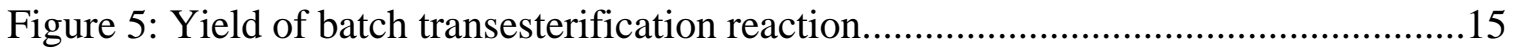

\section{Table of Tables}

Table 1: Reagent Ratios in Transesterification .........................................................6

Table 2: Peak Shifts Observed from Samples of Methyl Esters and Soybean Oil .............9

Table 3: Pressurized Transesterification, 3600 rpm, 5.1:1 Phase Ratio ...........................14

Table 4: Mole Ratios for Triglyceride, Glycerine, and Methyl Ester by NMR.................16

Table 5: Yields of Transesterification, Sequential Pressurized 2-min Stages ...................16 


\section{Executive Summary}

Oak Ridge National Laboratory (ORNL) and Nu-Energie, LLC entered into a Cooperative Research And Development Agreement (CRADA) for the purpose of demonstrating and deploying a novel technology for the continuous synthesis and recovery of biodiesel from the transesterification of triglycerides. The focus of the work was the demonstration of a combination Couette reactor and centrifugal separator-an invention of ORNL researchers - that facilitates both product synthesis and recovery from reaction byproducts in the same apparatus.

At present, transesterification of triglycerides to produce biodiesel is performed in batchtype reactors with an excess of a chemical catalyst, which is required to achieve high reactant conversions in reasonable reaction times (e.g., 1 hour). The need for long reactor residence times requires use of large reactors and ancillary equipment (e.g., feed and product tankage), and correspondingly large facilities, in order to obtain the economy of scale required to make the process economically viable. Hence, the goal of this CRADA was to demonstrate successful, extended operation of a laboratory-scale reactor/separator prototype to process typical industrial reactant materials, and to design, fabricate, and test a production-scale unit for deployment at the biodiesel production site.

Because of its ease of operation, rapid attainment of steady state, high mass transfer and phase separation efficiencies, and compact size, a centrifugal contactor was chosen for intensification of the biodiesel production process. The unit was modified to increase the residence time from a few seconds to minutes ${ }^{*}$. For this application, liquid phases were introduced into the reactor as separate streams. One was composed of the methanol and base catalyst and the other was the soy oil used in the experiments. Following reaction in the mixing zone, the immiscible glycerine and methyl ester products were separated in the high speed rotor and collected from separate ports.

Results from laboratory operations showed that the ASTM specification for bound acylglycerides was achieved only at extended reaction times ( $25 \mathrm{~min})$ using a singlestage batch contact at elevated temperature and pressure. In the single-pass configuration, the time required gives no throughput advantage over the current batch reaction process. The limitation seems to be the presence of glycerine, which hinders complete conversion because of reversible reactions. Significant improvement in quality was indicated after a second and third passes, where product from the first stage was collected and separated from the glycerine, and further reacted with a minor addition of methanol. Chemical kinetics calculations suggest that five consecutive stages of 2 min residence time would produce better than ASTM specification fuel with no addition of methanol past the first stage. Additional stages may increase the capital investment, but the increase should be offset by reduced operating costs and a factor of 3 higher throughput.

\footnotetext{
* Patent pending (2009).
} 


\section{Purpose and Background}

Biodiesel, a mixture of methyl esters, is made commercially from the transesterification of oil [1], often soy oil (see Reaction 1). The kinetics of the transesterification process is rapid; however, multiphase separations after the synthesis of the fuel can be problematic. Therefore, the process is typically run in batch mode. The biodiesel fuel and the glycerine product take several hours to separate. In addition, to push yields to completion, an excess of methoxide catalyst is typically used, which has to be removed from both the biodiesel and the glycerine phase after reaction. Washing steps are often employed to remove free fatty acids, which can lead to undesirable saponification. Standards for biodiesel purity are based either on the removal of contaminants before the oil feedstock is esterified or on the separation of unwanted by-products [2].

$$
\begin{gathered}
\mathrm{C}_{3} \mathrm{H}_{5}\left(\mathrm{CO}_{2} \mathrm{R}^{1}\right)\left(\mathrm{CO}_{2} \mathrm{R}^{2}\right)\left(\mathrm{CO}_{2} \mathrm{R}^{3}\right)+3 \mathrm{CH}_{3} \mathrm{OH} \rightarrow \mathrm{CH}_{3} \mathrm{O}_{2} \mathrm{R}^{1}+\mathrm{CH}_{3} \mathrm{O}_{2} \mathrm{R}^{2}+\mathrm{CH}_{3} \mathrm{O}_{2} \mathrm{R}^{3}+\mathrm{C}_{3} \mathrm{H}_{8} \mathrm{O}_{3} \\
\text { Triglyceride }+ \text { Methanol } \square \text { Methyl Esters + Glycerine }
\end{gathered}
$$

Various methods have been examined to enhance either the pretreatment of biodiesel feedstocks or the posttreatment of reaction products, including the use of a cavitation reactor in the process intensification of the homogeneous acid catalysis of transesterification [3]. Centrifugal mixing has been applied to biodiesel production, using the contactor as a low-throughput homogenizer, employing very low flow rates to increase residence times to tens of minutes [4]. In this study, we have combined the reaction of oil and methoxide with the online separation of biodiesel and glycerine into one processing step, using a modified centrifugal contactor. Two distinct phases enter the reactor (reagents), and two distinct phases leave the reactor/separator (products), thus demonstrating the application of process intensification to high-throughput biofuel production.

ORNL has been designing, fabricating, and operating centrifugal contactors for the selective extraction of actinide elements for over 25 years. Centrifugal phase contact and separation is an example of an intensified technique that enhances mass transfer at high throughput and minimizes the inventory of solvents. Such methods are well suited for applications in treatment of nuclear waste [5] and nuclear fuel recycling [6]. Contactors for such uses are available commercially and have been tested in processing of actual radioactive feeds [7]. Contactor technology has also been tested in the area of oil recovery, enhancing the separation of produced water from the lighter hydrocarbon phase [8]. In all of these solvent extraction applications, the process has been optimized to maximize mixing followed by phase separation with minimal residence time, a sequence that is necessary in nuclear applications to minimize solvent degradation from radiolysis. Hence, the conventional design is unsuitable for biodiesel synthesis, necessitating significant modifications $[9,10]$. 


\section{Methods and Materials}

Centrifugal contactors were initially developed as solvent extraction devices for use in actinide recovery from spent nuclear reactor fuel as an evolution of mixer-settlers [7]. The distinctive feature of the centrifugal contactor apparatus is the use of rotor within a stationary cylinder (the housing) to accomplish both the intimate mixing of two immiscible solutions to produce a dispersion and to generate centrifugal force used to separate the dispersion. In conventional applications, the generation of finely divided dispersion promotes the selective transfer of one or more solutes from one liquid phase into another. This transfer is accomplished by means of Couette mixing; the creation of shear forces in solutions contained within the annulus between a stationary outer cylinder and a rotating inner cylinder (Figure 1). The mixture then enters the rotor where centrifugal forces separate the light and heavy phases. Collection weirs at the top of the rotor direct the light and heavy phases to separate ports on the reactor.

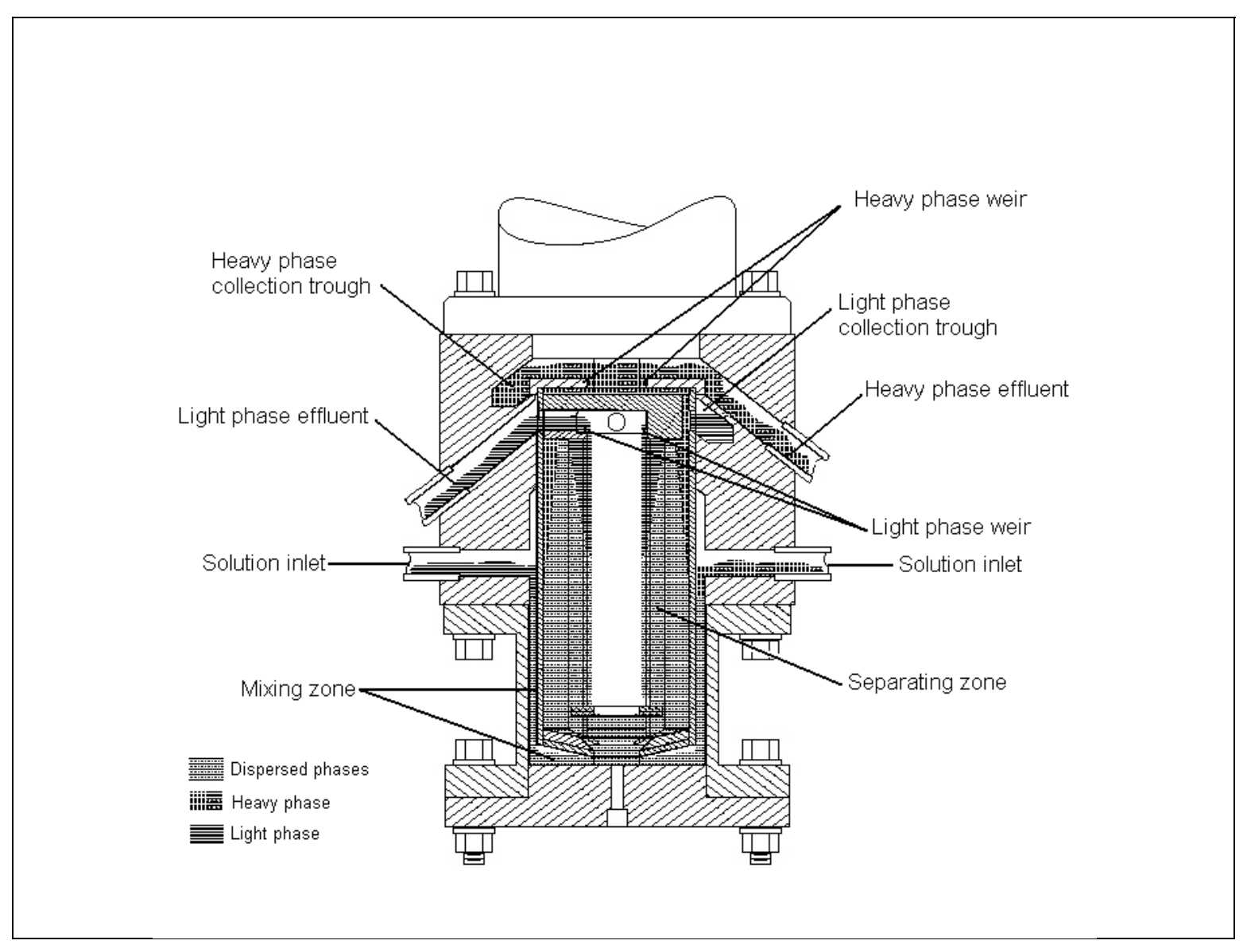

Figure 1: Schematic of Standard Centrifugal Contactor.

The contactor pictured above minimizes mass-transfer limitations in the reaction kinetics in the mixing zone, and also effectively separates the phases in a continuous-flow operation. It allows high throughput, and can be used for intensified processing by 
combining reaction and phase separation, providing intensive mixing, allowing a short residence time, and requiring a small footprint. The centrifugal contactor used in the laboratory, Costner Industries Texas \#V-2 5-cm-diameter stainless-steel, has a rotor that is normally operated above $3000 \mathrm{rpm}$.

In the configuration for biodiesel production, the contactor pictured above was modified to increase the mixing time from about 10 seconds to over a minute. Changes were made to the inlet between the mixing and separating zones to reduce the pumping rate from the outer to the inner chamber. In addition, sampling and recirculation zones were incorporated into the design to facilitate monitoring of the transesterification reaction, online sampling, and addition of reagent (methanol/methoxide) at high pressures. A version of the reactor with a longer body was designed and built, to minimize splashing from one zone to another.

The advantage of this device over previously described centrifugal reactors (e.g., by Peterson and coworkers [11]) is that the increased residence time is integrated into the unit design and additional delay loops and processing are not required.

\section{$\underline{\text { Reagents }}$}

Reagents were soybean oil, methanol, and 30\% methanol/methylate (all from NuEnergie, LLC) ${ }^{\dagger}$, at volumetric phase ratios from 4:1 to $6: 1$ oil/methanol (see Table 1). In addition, some continuous-flow experiments were carried out using potassium methylate and corn oil as discussed later. The variation in phase ratio was done to investigate the dependence of the yield of methyl esters on the amount of catalyst. These phase ratios were used for both the static and flow-through experiments. The standard volumetric ratio was the same as the one used at the Nu-Energie plant, i.e., 5.1:1. All reagents were used without further purification. The acid number of the feedstock oil was determined by titration with alcoholic $\mathrm{KOH}$ to be $0.06 \pm 0.01 \mathrm{mg} \mathrm{KOH} / \mathrm{g}$. In the static experiments, the oil was preheated to the desired temperature before addition of the methanol/methylate mixture.

\footnotetext{
${ }^{\dagger}$ http://www.nu-energie.com/
} 
Table 1: Reagent Ratios in Transesterification

\begin{tabular}{|c|c|c|c|c|}
\hline $\begin{array}{c}\text { Oil/Methanol } \\
\text { Volumetric } \\
\text { Phase Ratio }\end{array}$ & $\begin{array}{c}\text { Methanol/ } \\
\text { Triglyceride } \\
\text { Mole Ratio }\end{array}$ & $\begin{array}{c}\text { Soybean Oil } \\
(\mathrm{mL})\end{array}$ & $\begin{array}{c}\text { Methanol } \\
(\mathrm{mL})\end{array}$ & $\begin{array}{c}\text { Methanol/30\% } \\
\text { Methylate } \\
(\mathrm{mL})\end{array}$ \\
\hline 4.25 & 5.62 & 150.0 & 31.7 & 3.6 \\
\hline 4.26 & 5.61 & 81.40 & 17.0 & 2.0 \\
\hline 4.37 & 5.42 & 81.4 & 15.8 & 2.8 \\
\hline 5.00 & 4.77 & 150.0 & 26.4 & 3.6 \\
\hline 5.06 & 4.71 & 83.5 & 14.5 & 2.0 \\
\hline
\end{tabular}

\section{Flow-Through Experiments in Centrifugal Contactor}

Base-catalyzed biodiesel synthesis and simultaneous separation of methyl ester and glycerine products were carried out in a modified centrifugal contactor. The reactor was operated in continuous mode up to $60^{\circ} \mathrm{C}$, with the phase ratio being controlled via the relative volumetric flow rates pumped to the reactor. Samples of product were taken from the lighter and heavier discharge ports of the reactor/separator. The total volumetric flow was set so as to obtain a mean reactor residence time of $1 \mathrm{~min}$. Five minutes were needed to establish stable flows through the contactor as the glycerine phase was only one tenth of the volume of the methyl ester phase. Samples were taken between 1 and 20 min after flow was initiated.

Although the average residence time was set as $1 \mathrm{~min}$, observations made during testing using a transparent Lucite housing with dyed feed solution indicated that the residence time distribution was broad, with a small amount material exiting the apparatus less than $10 \mathrm{~s}$ after introduction because of pulsing in the mixing zone. This effect could be reduced by lengthening of the contactor housing.

\section{Elevated Pressure Tests in Contactor Done with Single Charge of Reagents}

In testing performed at elevated (i.e., above ambient) pressure, the contactor was operated in batch mode, with the oil heated to temperature and the methanol injected at pressure into the housing. In these tests, the device was configured so as to prevent transfer of fluids from the reaction zone into the separating zone. Reaction products were removed directly from the reactor zone at the completion of each test. The lengths of batch-mode runs were varied to determine the progress of the reaction under pressures up to 2.6 bar and temperatures up to $80^{\circ} \mathrm{C}$.

\section{$\underline{\text { Analysis }}$}

For the kinetics data taken from the flow through experiments, reactions were halted by contact of the sample with an equal volume of $1 \mathrm{M} \mathrm{HCl}$. The samples were centrifuged, 
and the organic layer was separated and rinsed with twice the volume of deionized water to remove much of the unreacted methanol. Although most of the methanol was associated with the glycerine phase, a significant fraction remained in the methyl ester, and had to be removed prior to analysis.

Reaction products were analyzed by gas chromatography flame-ionization detection (GC FID), with a Hewlett Packard 5890 II GC. The analysis procedure followed ASTM D6854 [12]. Precision in the measured peak areas was estimated to be $\pm 10 \%$ from injection of reference standards. Infrared (IR) analysis of the products was performed using a Bruker FTIR spectrometer. The Bruker analyses were conducted by Nu-Energie LLC both on and off-site using the Cognis QTA system ${ }^{\ddagger}$, and were reported with a precision of $\pm 0.01 \mathrm{wt} \%$ in the triglyceride, diglyceride and monoglyceride components of the "bound" glycerine fraction. However, the accuracy of the results was estimated to be $\pm 0.1 \mathrm{wt} \%$ as the samples were greatly affected by preparative procedures, such as washing to remove excess methanol.

Changes in viscosity, measured with a Brookfield DV-E viscometer, were correlated with reaction yield and were used to monitor progress towards the ASTM standard in bound glycerine concentration $(<0.23 \mathrm{wt} \%)$. A calibration curve for viscosity measurements was developed using the Nu-Energie LLC commercial methyl ester product mixed with unreacted soy oil, washed and heated to remove any residual methanol in the same manner as the samples from the experiments (Figure 2). All viscosities were measured at $25^{\circ} \mathrm{C}$, as established using a water jacket on the viscometer and a thermostated water bath. The calibration samples were found to degrade over time, and so the accuracy of the percentage unreacted from the viscosity analysis was estimated to be $\pm 1 \mathrm{wt} \%$ unreacted oil.

\footnotetext{
‡ http://www.cognis.com/products/Business+Units/AgroSolutions/Grain+Analysis/

${ }^{\S}$ Bound glycerine refers to the wt\% of the glycerine backbone in the acylglyceride molecule.
} 


\section{Weight Fraction Bound Glycerine}

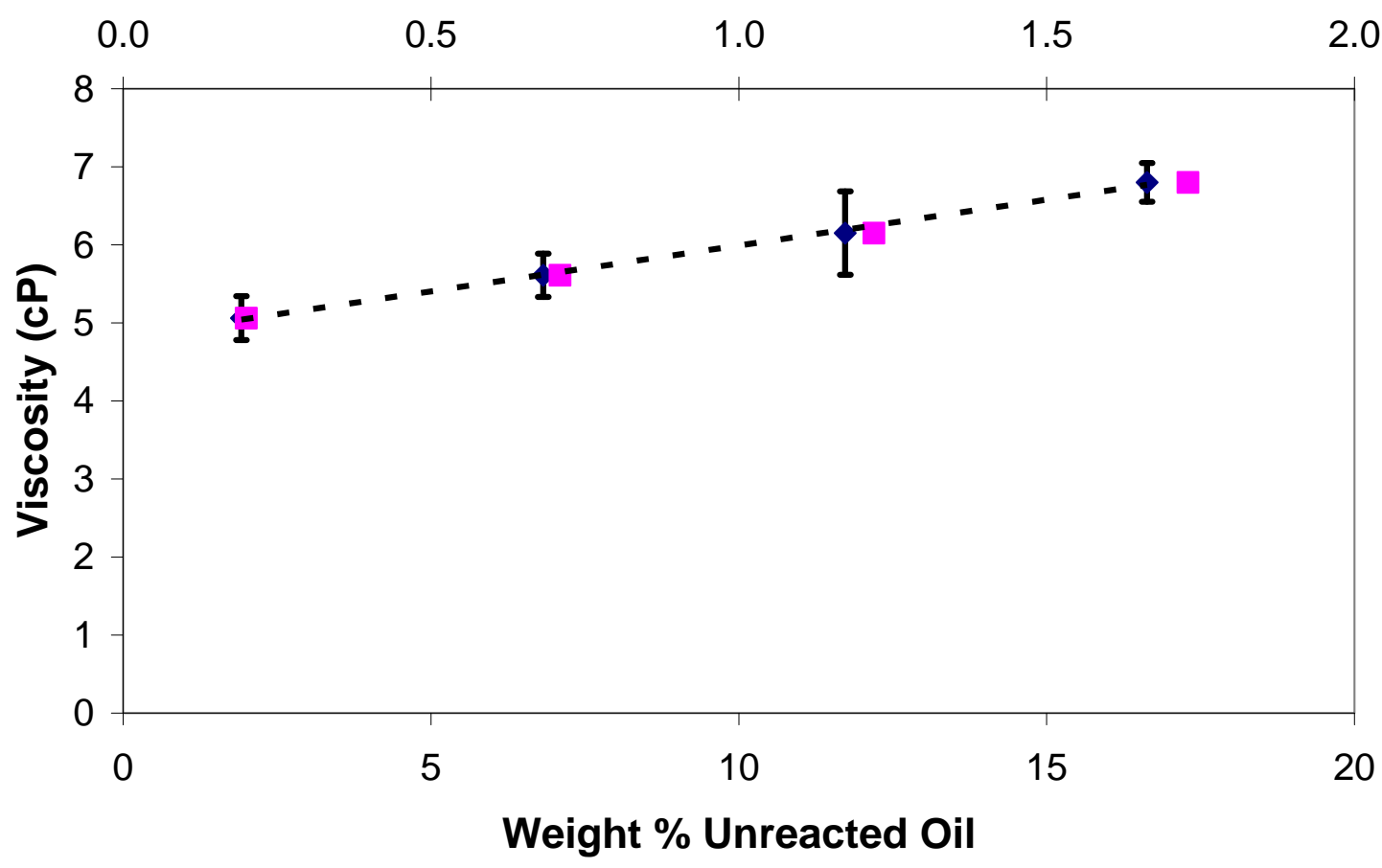

Figure 2: Calibration curve of viscosity as a function of bound glycerine in biodiesel at $25^{\circ} \mathrm{C}$. The weight fraction of bound glycerine ( ) is not identical to the amount of unreacted oil $(\diamond)$ as the latter does not include the diglycerides and monoglycerides.

Samples were also analyzed by $\mathrm{H}^{1} \mathrm{NMR}$ in a Bruker Avance-400 NMR after dissolution in $\mathrm{CDCl}_{3}$ (Aldrich, lot \#00808TH, 0.03\% v/v tetramethylsilane, TMS). Peak shifts are given in Table 2 and compared to the Sadtler compilation [13]. Because of the variety of constituent fatty acid chains, the peaks were generally quite broad, with the sharpest being the methyl group on the methyl-ester product, at $=3.7$. The peaks that were uniquely attributed to the acylglyceride were present at a shift between 4.1 and 4.3. A small peak at 3.6 could be attributed to hydrogen on free glycerine. 
Table 2: Peak Shifts Observed from Samples of Methyl Esters and Soybean Oil

\begin{tabular}{|c|c|c|c|}
\hline Shift relative to TMS & Splitting & Assignment & Sample \\
\hline 0.8 & Multiplet & Terminal $\mathrm{CH}_{3}$ & Soybean oil, methyl ester \\
\hline 1.3 & Doublet & $-\mathrm{CH}_{2}-$ & Soybean oil,methyl ester \\
\hline 2.0 & Multiplet & $-\mathrm{CH}_{2}$ - beta to $\mathrm{C}=\mathrm{O}$ & Soybean oil, methyl ester \\
\hline 2.3 & Triplet & $-\mathrm{CH}_{2}$ - alpha to $\mathrm{C}=\mathrm{O}$ & Soybean oil, methyl ester \\
\hline 2.8 & Triplet & $-\mathrm{H}$ to double bond & Soybean oil, methyl ester \\
\hline 3.6 & Singlet & Free-glycerine $\mathrm{H}$ & Methyl ester \\
\hline 3.7 & Singlet & $\mathrm{CH}_{3}-\mathrm{O}-$ & Methyl ester \\
\hline $4.1-4.3$ & Multiplet & H on glycerine backbone & Soybean oil \\
\hline 5.3 & Multiplet & $-\mathrm{H}$ to double bond & Soybean oil, methyl ester \\
\hline
\end{tabular}

\section{Results and Discussion}

Work to be performed was divided into three major tasks: optimization and demonstration of the technology in lab-scale, short-duration testing, longer duration testing performed at laboratory scale to confirm process and equipment reliability, and design, fabrication, and testing of an industrial scale reactor/separator.

\section{$\underline{\text { Laboratory-Scale Test Activities }}$}

A centrifugal contactor, Costner Industries Texas \#V-2, 5-cm-diameter stainless-steel, was purchased from CINC and modified as described above. The contactor was operated in two modes, a flow through configuration as envisioned for commercial installation and in batch mode. The contactor rotor was normally run at $3600 \mathrm{rpm}$, although testing also took place at 3000,4200 , and $4800 \mathrm{rpm}$.

\section{Flow-through experiments}

Kinetic data from flow through experiments were collected on an oil-to-methanol phase ratio of 5 at ambient pressure. This was achieved by separately introducing potassium methoxide ( $0.44 \mathrm{M} \mathrm{KOH}$ in methanol) and corn oil into the mixing zone of the contactor at flow rates of 10 and $50 \mathrm{~mL} \cdot \mathrm{min}^{-1}$ respectively. Reagents and the contactor were heated to $60^{\circ} \mathrm{C}$ prior to being mixed. Samples were collected from the outlets of the contactor at $1,3,6$, and 10 min after the beginning of the experiment, and were neutralized immediately. Gas chromatographic analyses of product streams from the continuous centrifugal contactor syntheses are shown in Figures 3 and 4. A sample was also taken 
from the reactor at the end of the test, and represents the "equilibrium" sample on the graph.

The bars show the fraction of unreacted oil versus methyl ester coming from the "light" and "heavy" fractions, respectively. Because of the difference in yield, the flow of glycerine-rich dense phase was much slower than that of the biodiesel. As a result, separation was initially poor and methyl ester was found in both of the streams. After approximately a minute, the flows settled down and the methyl ester and glycerine were well separated. Except at the beginning of the experiment, when mixing and flows were being established, no unreacted oil was present in the "light"-side fraction. The data in Figure 4 show that over time, the fraction of methyl ester in the "heavy"-side flow decreased dramatically as the flow of glycerine was established. However, because the system was configured to achieve the highest purity on the "light" side, some oil and methyl ester remained entrained into the denser phase. The residual samples were drained from the bottom of the reactor well after the timed experiment was complete. These samples showed that the centrifugation process was more effective at separation of the product phases than could be achieved in using an alternative processer such as a mixersettler, which relies on gravity. The effective separation in the contactor resulted from enhanced mass transfer from application of centrifugal forces equivalent to approximately 300 times that of gravity. The slight drop in signal at 6 and 10 min after the experiment started, Figure 3, is within the precision of the GC analysis.

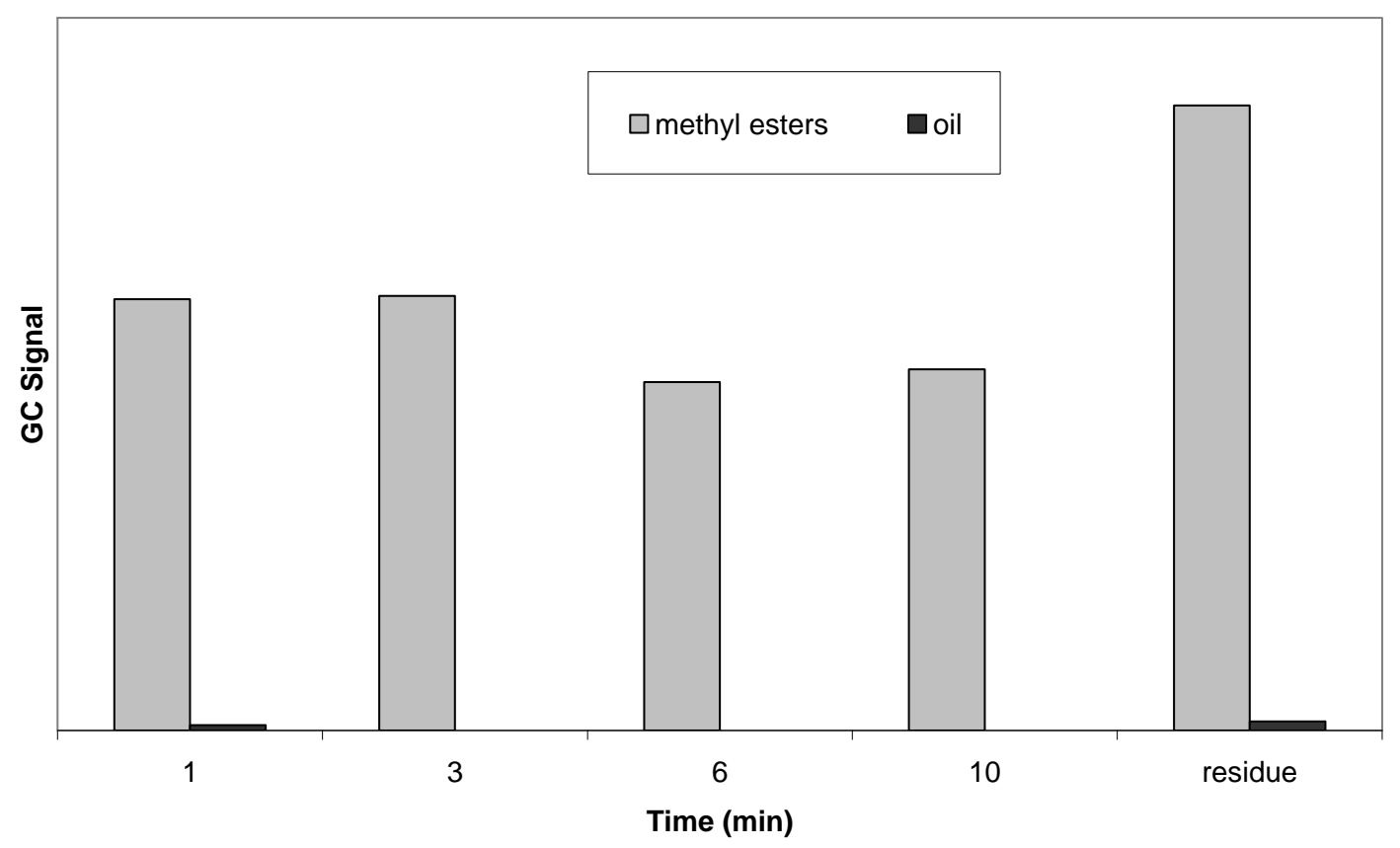

Figure 3: GC analysis of less-dense fluid from the continuous production of biodiesel. 


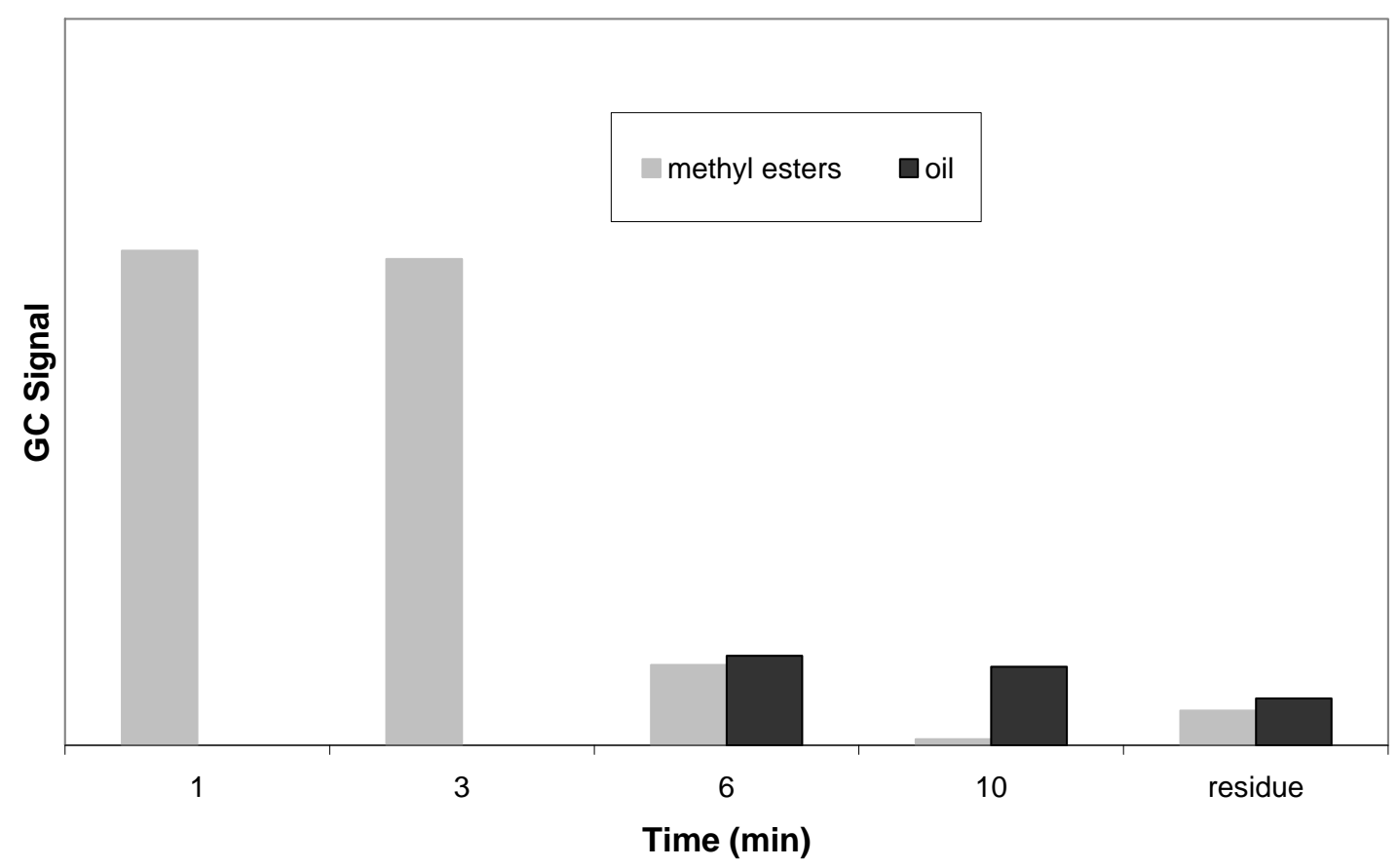

Figure 4: GC analysis of more-dense fluid from the continuous production of biodiesel.

Most of the flow-through contactor experiments were carried out using sodium methylate and soy biodiesel from Nu-Energie as discussed earlier, Table 1. The products from these experiments were analyzed with the Bruker IR spectrometer. Disappointingly, the results showed significant contamination of the methyl ester with oil, unlike the earlier results from the gas chromatograph. Modifications to the contactor to further increase the mean residence time likely also broadened the range of residence time. This was confirmed by the experiments in a clear-housing contactor that allowed visual observation of the mixing zone. Hence, only qualitative information could be gained from the latter continuous-flow tests, such as the time at which steady-flows were established through the reactor outlets - carried out at phase ratios ranging from 5.0 to 6.0 oil-to-methanol and rotor speeds of 3600 and $4200 \mathrm{rpm}$. With the exception of the flow at the ratio of 5.0 and rotor speed of $3600 \mathrm{rpm}$, all of the tests indicated steady-state flow being achieved within $5 \mathrm{~min}$. Using a higher rotor speed of $4200 \mathrm{rpm}$ at the 5.0 ratio appeared to increase the yield of the transesterification reaction and achieve steady-state earlier than at 3600 rpm.

\section{Batch Experiments}

It became apparent from IR analysis of product from the continuous flow experiments that the contactor had to be operated at elevated pressures to achieve ASTM specification grade methyl ester. This necessitated operation in "batch" mode, as the laboratory was 
not equipment with auxiliary equipment (feed and storage tanks) that could be pressurized. Temperatures up to $80^{\circ} \mathrm{C}$ were achieved with heating tape and PID temperature control based on thermocouple readings. Pressurization was achieved by filling with dry inert gas, $\mathrm{N}_{2}$, from a high pressure cylinder.

Results from the pressurized reactor tests from both IR analysis and viscosity measurements are given in Table 3. Unless otherwise noted, all of the tests were done at the standard volumetric phase oil-to-methanol ratio of 5.1:1. Conditions of the reaction are also shown in the table, including the maximum pressure and temperature reached. For the tests done under pressure, the operating conditions that worked best were to slightly pressurize the reactor containing the oil with dry nitrogen as it was heated to approximately $80^{\circ} \mathrm{C}$. The pressure increased rapidly after injection of the methanol, indicative of the progress of the transesterification reaction, and dropping again once steady state had been reached after a few minutes. Sampling in this case could only be done at the end of the test, as it involved depressurizing the vessel, so each of the data points came from a separate run. Results from viscosity measurements, Figure 5, show the approach to ASTM standard for bound glycerine $(<0.23 \mathrm{wt} \%)$. The graph also shows a slow increase in yield from $90 \%$ completion at $2 \mathrm{~min}$. Interpolation of these data suggests the minimum time for achievement of ASTM standard in one pass appears to be $25 \mathrm{~min}$.

Reaction yields measured using IR spectroscopy are presented in Table 3, columns 2-6, and from viscosity measurements, column 7 . However, as can be seen from the last four entries in Table 3, the increase in reaction yield for mixtures that were passed through the reactor twice is quite dramatic, giving results after a total reaction time of $10 \mathrm{~min}$ of over 95\% completion; results that are comparable to a single pass reaction time of $15 \mathrm{~min}$. The second reaction stage involved injection of a small addition of methanol, less than $1 \mathrm{~mL}$.

The overall variability in the results is indicative of the sensitivity of the methods to small errors in sampling, such as cross-contamination of sampling lines in the contactor, and is considerably greater than the measurement precisions possible for the analytical procedures, which are given in the table.

Although not given in the table 3 , several tests were carried out at 50 and $60^{\circ} \mathrm{C}$, at ambient pressure and an oil-to-methanol volumetric phase ratio of 5.1:1.

Transesterification yields were not as good as for $80^{\circ} \mathrm{C}$ tests, and hence the results are not presented in detail here. In addition, a batch tests undertaken at a rotor speeds of 3000 and $4800 \mathrm{rpm}$ both showed a lower conversion to products than the tests done at 3600 rpm, suggesting that for the $10-\mathrm{cm}$-dia contactor a rotor speed of $3600 \mathrm{rpm}$ is optimal. 
Table 3: Pressurized Transesterification, 3600 rpm, 5.1:1 Phase Ratio

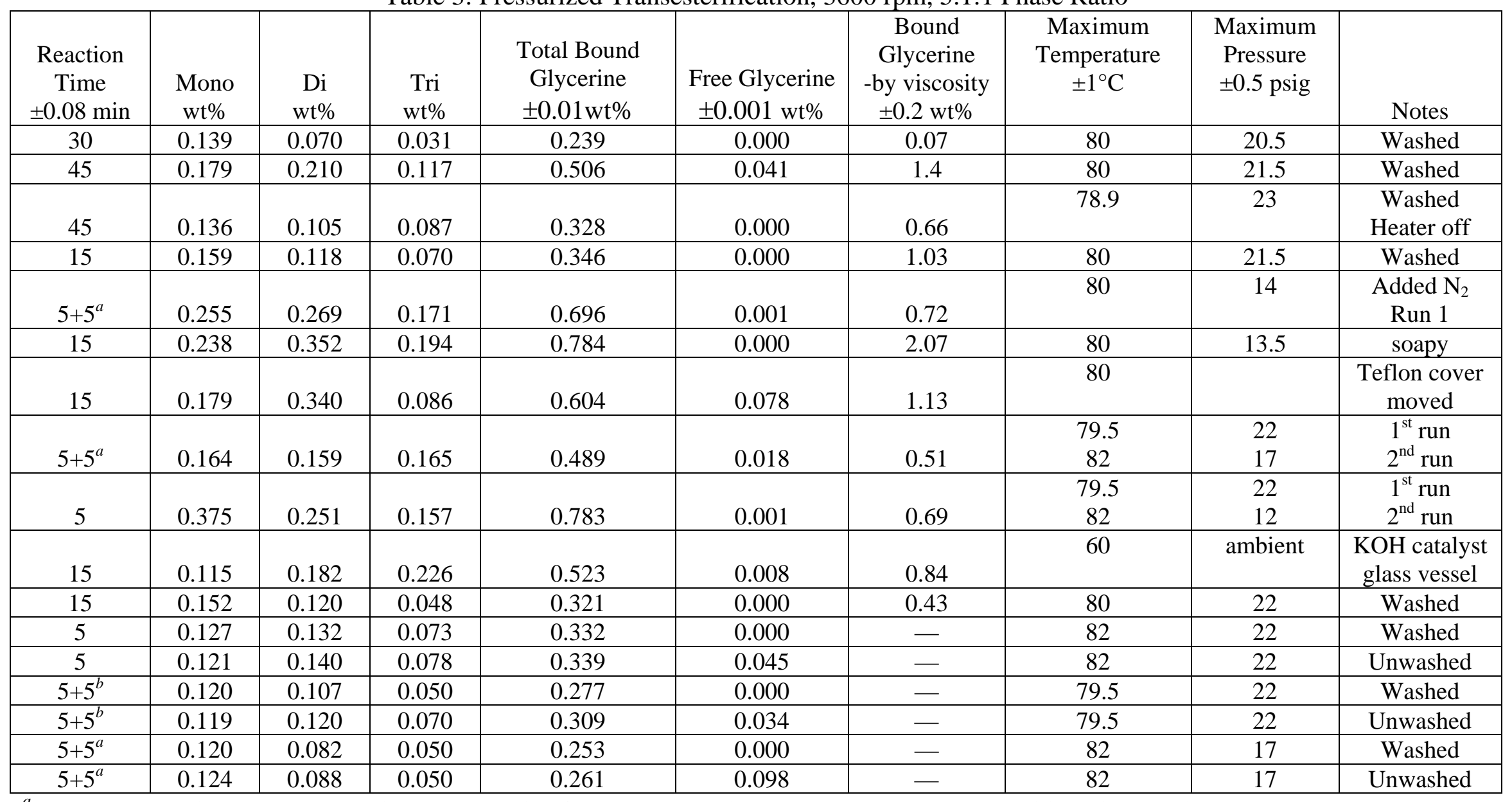

${ }^{a}$ Methanol added in second pass to give volume ratio of 5:1 unreacted triglyceride to methanol. No addition of methoxide catalyst.

${ }^{b}$ No additional methanol added in second pass. 


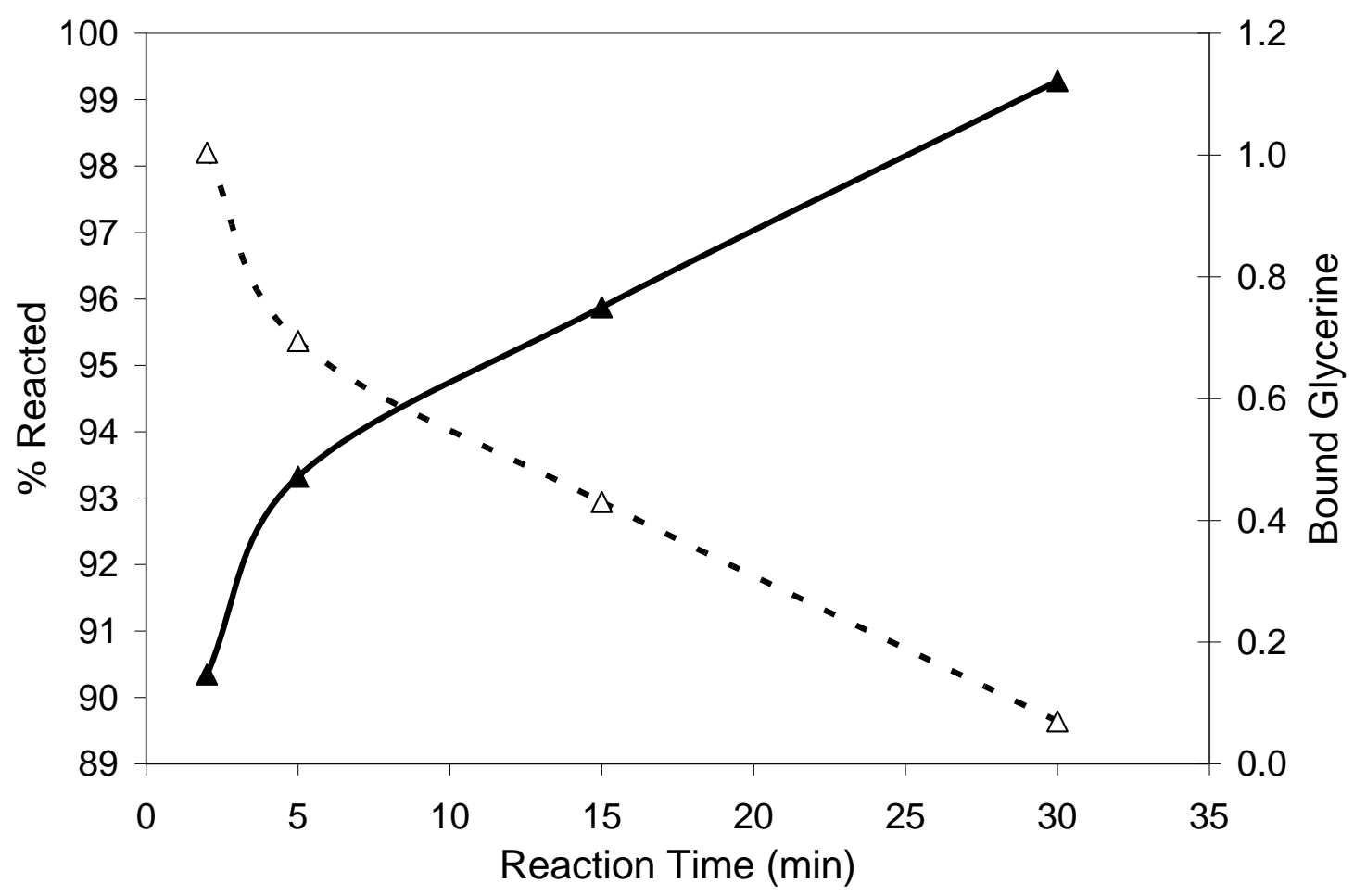

Figure 5: Yield of batch transesterification reaction, in terms of the weight percent of triglyceride reacted ( ) and in remaining total bound glycerine ( ) as a function of reaction time $\left(80^{\circ} \mathrm{C}\right.$, above ambient pressure, $3600 \mathrm{rpm}$ rotor speed $)$.

Results from analyzing the viscosity of methyl-ester product are shown in Figure 5. These results indicate that the methanolysis reaction was about $90 \%$ complete after 2 min (maximum temperature of $80^{\circ} \mathrm{C}$ at $2.6 \mathrm{bar}$ ), which would be an optimal residence time for the design of a commercial reactor-separator. Thus, to achieve ASTM specification fuel, i.e., $<0.23 \mathrm{wt} \%$ total glycerine, two or three cross-current reactors would be needed in series, with the by-product glycerine being separated from the triglyceride/methyl ester mixture in stages. A small injection of methanol into the second stage would increase the yield further.

\section{Extended Laboratory-scale Demonstration}

The results of earlier tests showed that optimal processing of oil to methyl ester would take place at above ambient pressures and temperatures up to $80^{\circ} \mathrm{C}$. The analysis of yields as a function of reaction time suggested that although a short residence time would not give ASTM specification grade biodiesel, a series of reaction stages had the potential for achieving this goal. Hence, consecutive transesterification runs to produce biodiesel were carried out, each with a residence time of two minutes. 
As with all the pressurized tests, the runs were done with the contactor in static mode with first the oil introduced into the vessel, followed by injection of the methanol/base injected. In these tests, unlike those described in the earlier section, reagents were not heated before being added to the reaction vessel, but the vessel itself was taken up to temperature before starting the transesterification reaction. The mixing was stopped after two minutes. The contactor was promptly vented, and the samples were taken for further reaction and NMR analysis.

The analysis was done by diluting the samples in $\mathrm{CDCl}_{3}$ spiked with TMS, and using a Bruker Avance 400. Data from the analysis is presented below with the peaks at shifts 4.1-4.2 being attributed to the five glycerine protons bonded to carbon, and the singlet at 3.7 attributed to the 3 protons on the methyl moiety. A singlet at 3.6 is attributed to the protons bonded to the oxygen on glycerine, showing up in the reaction mixture but not with the unreacted oil. The mole ratios were taken from peak areas, normalized to the number of protons contributing to the signal.

Table 4: Mole Ratios for Triglyceride, Glycerine, and Methyl Ester by NMR

\begin{tabular}{|l|l|l|}
\hline $\begin{array}{l}\text { Contactor stages } \\
\text { min reaction at } 80^{\circ} \mathrm{C},\end{array}$ & $\begin{array}{l}\text { Mole ratio } \\
\text { acylglyceride/methyl ester } \\
\text { overpressure }\end{array}$ & $\begin{array}{l}\text { Mole ratio } \\
\text { OH/methyl ester } \\
\text { (free glycerine) }\end{array}$ \\
\hline Stage 1 & 0.046 & negligible \\
\hline Stage 2 & 0.051 & 0.058 \\
\hline Stage 3 & 0.029 & 0.051 \\
\hline
\end{tabular}

The mole ratios above are converted to the more conventional weight \% bound and free glycerine. The free glycerine values are fairly high because these samples were not washed between stages. Also, some of the free glycerine may be attributed to mono and diglycerides - hence the range given in the table. The \% completion is also computed assuming that the \% bound is completely from the triglyceride - also a conservative approach. As normally done, this is based on the weight \% oil remaining, as each molecule of triglyceride splits into 3 molecules of product. The target is included in the last row of the table in italics.

Table 5: Yields of Transesterification, Sequential Pressurized 2-min Stages

\begin{tabular}{|l|l|l|l|}
\hline Contactor stages & \% bound & \% free (upper limit) & \% completion \\
\hline Stage 1 & 0.46 & Negligible & 95.6 \\
\hline Stage 2 & 0.50 & $1.4-2.9$ & 95.2 \\
\hline Stage 3 & 0.29 & $1.6-2.6$ & 97.2 \\
\hline GOAL & 0.23 & 0.02 & 97.8 \\
\hline
\end{tabular}

The results show that the staged approach does help move the reaction towards the target. The small difference between results from stage 1 and stage 2 is likely an indicator of the uncertainty in the analysis; however, the increase in the peak at 3.6 suggests that the diand monoglycerides are likely being formed at the expense of the triglyceride between the two runs. 


\section{$\underline{\text { Production-scale Technology Verification }}$}

A larger residence time reactor-separator was designed based on the 10-cm-dia. rotor contactor. In this new configuration, the rotor body and housing were extended in length from the original. The goal was to eliminate the small fraction of oil that experienced a very short residence time because of splashing during the mixing process. A housing was fabricated based on this new design. Testing of the reactor separator will take place when the Surgoinsville plant is operational, which depends on current market conditions for biodiesel.

\section{Conclusions}

Laboratory experiments were carried out to understand the process of transesterification in a centrifugal contactor. As the results describe, the ASTM specification for bound acylglycerides was achieved only at extended reaction times using a single-stage batch contact at elevated temperature and pressure. In the single-pass configuration, the time required gives no throughput advantage over the current batch reaction process. The limitation seems to be the presence of glycerine, which hinders complete conversion because of reversible reactions. Significant improvement in quality was indicated after second and third passes, where product from the first stage was collected and separated from the glycerine, and further reacted with a minor addition of methanol. A kinetic analysis suggests that the explanation for this improvement lies with the reduction in back reactions hindering overall reaction progress to methyl esters.

Chemical kinetics calculations suggest that five stages consecutive stages of $2 \mathrm{~min}$ residence time would produce better than ATSM specification fuel with no addition of methanol past the first stage. This would be reduced if small amounts of methanol were added to the reaction mixture after the first stage. Additional stages may increase the capital investment, but the increase should be offset by reduced operating costs and an estimated factor of 3 higher throughput.

\section{Acknowledgments}

Preliminary research was sponsored by the Laboratory Directed Research and Development Program of Oak Ridge National Laboratory, managed by UT-Battelle, LLC, for the U. S. Department of Energy contract \#DE-AC05-00OR22725. Funding for this project was provided in part by the Department of Energy's Office of Energy Efficiency and Renewable Energy's Technology Commercialization and Deployment Program's Technology Commercialization Fund and by Nu-Energie LLC under CRADA \#01377. 


\section{References}

1. Freedman, B., E.H. Pryde and T.L. Mounts (1984), "Variables Affecting the Yields of Fatty Esters from Transesterified Vegetable Oils,” J. Amer. Oil Chem. Soc., 61(10), pp. 1638-1643.

2. ASTM International (2008), ASTM Standard D6751-07b, "Standard Specification for Biodiesel Fuel Blend Stock (B100) for Middle Distillate Fuels.”

3. Kelkar, M.A., P.R. Gogate and A.B. Pandit (2008), "Intensification of Esterification of Acids for Synthesis of Biodiesel Using Acoustic and Hydrodynamic Cavitation,” Ultrasonics Sonochemistry, 15, pp. 188-194.

4. Kraai, G.N., F. van Zwol, B. Schuur, H.J. Heeres and J.G. de Vries (2008), "TwoPhase (Bio)Catalytic Reactions in a Table-Top Centrifugal Contact Separator,” Angew. Chem., 47, 3905-3908.

5. Geeting, M.W., E.A. Brass, S.J. Brown and S.G. Campbell (2008), “Scale-up of Caustic-Side Solvent Extraction Process for Removal of Cesium at Savannah River Site,” Sep. Sci. Technol., 43, pp. 2786-2796.

6. Taylor, R.J. and I. May (2001), “Advances in Actinide and Technetium Kinetics for Applications in Process Flowsheet Modeling,” Sep. Sci. Technol., 36, pp. 1225-1240.

7. Leonard, R.A., G.J. Bernstein, A.A. Ziegler and R.H. Pelto (1980). “Annular Centrifugal Contractors for Solvent-Extraction,” Sep. Sci. Technol., 15(4), pp. 925-943.

8. Klasson, K.T., P.A. Taylor, J.F. Walker, S.A. Jones, R.L. Cummins and S.A. Richardson (2005), "Modification of a Centrifugal Separator for in-Well OilWater Separation,” Sep. Sci. Technol., 40, pp. 453-462.

9. $\quad$ Tsouris, C.; McFarlane, J.; Birdwell, J. F., Jr.; Jennings, H. L. (2008), "Continuous Production of Biodiesel via an Intensified Reactive/Extraction Process. In Solvent Extraction. Fundamentals to Industrial Applications. Proceedings of ISEC 2008. International Solvent Extraction Conference. B. Moyer, Ed.; Canadian Institute of Mining, Metallurgy and Petroleum, Montréal, Canada, 2008; pp 923-930.

10. McFarlane, J., Birdwell, J. F. Jr., Tsouris, C., Jennings, H. (2008), “Process Intensification in Continuous Base-Catalyzed Biodiesel Production”. In Proceedings of the 2008 AIChE Fall - Annual Meeting, Philadelphia, PA, November 2008.

11. Peterson, C. L.; Cook, J. L.; Thompson, J. C.; Taberski, J. S. (2001), “Continuous Flow Biodiesel Production.” App. Eng. Ag. 18, 5.

12. ASTM Method D6854. Standard Test Method for the Determination of Free and Total Glycerin in B-100 Biodiesel Methyl Esters by Gas Chromatography. ASTM International, 2007.

13. Sadtler Research Laboratories. Proton NMR Collection, Philadelphia, 1980. 


\section{Appendix A Task Descriptions in Scope of Work}

\section{$\underline{\text { Laboratory-Scale Test Activities }}$}

\begin{tabular}{|c|l|}
\hline Task No. & \multicolumn{1}{|c|}{ Description } \\
\hline 1 & $\begin{array}{l}\text { Purchase a commercially-available centrifugal solvent extraction } \\
\text { contactor of standard design }\end{array}$ \\
\hline 2 & $\begin{array}{l}\text { Fabricate reactor/separator by modifying commercial centrifugal } \\
\text { contactor per details of ORNL invention }\end{array}$ \\
\hline 3 & Configure reactor/separator for laboratory-scale testing \\
\hline 4 & $\begin{array}{l}\text { Prepare and review experiment plans for evaluating and optimizing } \\
\text { device performance (focus on effects of variations in device physical } \\
\text { parameters and gas sparging) }\end{array}$ \\
\hline 5 & $\begin{array}{l}\text { Perform verification testing of new reactor/separator under conditions } \\
\text { identical to those used in previous proof-of-principle tests }\end{array}$ \\
\hline 6 & $\begin{array}{l}\text { Perform laboratory testing investigating the ability to mitigate the use of } \\
\text { excess catalyst }\end{array}$ \\
\hline 7 & $\begin{array}{l}\text { Investigate process/equipment performance as a function of feed source } \\
\text { (e.g.., use of various oils) }\end{array}$ \\
\hline
\end{tabular}

\section{$\underline{\text { Extended Laboratory-scale Demonstration }}$}

\begin{tabular}{|c|l|}
\hline Task No. & \multicolumn{1}{c|}{ Description } \\
\hline 8 & $\begin{array}{l}\text { Perform extended (lab/engineering-scale) production demonstration at } \\
\text { Nu-Energie location }\end{array}$ \\
\hline
\end{tabular}

\section{$\underline{\text { Production-scale Technology Verification }}$}

\begin{tabular}{|c|l|}
\hline Task No. & \multicolumn{1}{|c|}{ Description } \\
\hline 9 & Design production-scale reactor/separator \\
\hline 10 & Procure/fabricate production-scale reactor/separator \\
\hline 11 & Install production-scale reactor/separator at Nu-Energie site for testing \\
\hline 12 & Perform verification testing at Nu-Energie production facility \\
\hline 13 & Issue Final Report \\
\hline
\end{tabular}

